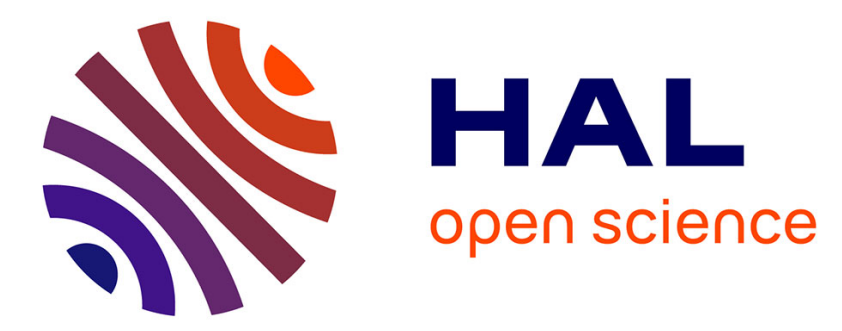

\title{
Consideration of climate change-induced corrosion by structural codes
}

Maria Nogal, Emilio Bastidas-Arteaga, Helena Maria dos Santos Gervásio

\section{To cite this version:}

Maria Nogal, Emilio Bastidas-Arteaga, Helena Maria dos Santos Gervásio. Consideration of climate change-induced corrosion by structural codes. IABSE Congress, Christchurch 2021: Resilient technologies for sustainable infrastructure, Feb 2021, Christchurch, New Zealand. pp.1064-1070, 10.2749/christchurch.2021.1064 . hal-03253209

\section{HAL Id: hal-03253209 \\ https://hal.science/hal-03253209}

Submitted on 8 Jun 2021

HAL is a multi-disciplinary open access archive for the deposit and dissemination of scientific research documents, whether they are published or not. The documents may come from teaching and research institutions in France or abroad, or from public or private research centers.
L'archive ouverte pluridisciplinaire HAL, est destinée au dépôt et à la diffusion de documents scientifiques de niveau recherche, publiés ou non, émanant des établissements d'enseignement et de recherche français ou étrangers, des laboratoires publics ou privés. 


\title{
Consideration of climate change-induced corrosion by structural codes
}

\author{
Maria Nogal \\ Faculty of Civil Engineering \& Geosciences, Delft University of Technology, Netherlands
}

\section{Emilio Bastidas-Arteaga}

Research Institute in Civil and Mechanical Engineering UMR CNRS 6183, University of Nantes, France

\author{
Helena Maria dos Santos Gervásio \\ Department of Civil Engineering, Coimbra University, Portugal
}

Contact: $\underline{\text { m.nogal@tudelft.nl }}$

\begin{abstract}
The impact of climate change on ambient temperature and relative humidity along with the present $\mathrm{CO}_{2}$ levels are speeding the corrosion process of reinforced concrete structures. The alarming cost of the associated reduction of the service life of structures, which is estimated to cost $3 \%$ to $4 \%$ of the Gross Domestic Product (GDP) of industrialized countries, has put the spotlight on the importance of introducing the issue of climate change on the new generation of Eurocodes. Amongst the strategies to tackle the problem, design-phase measures seem not to be always costeffective, nevertheless, measures during service-life are generally the most expensive. This paper discusses the potential strategies to be addressed by structural codes to tackle the problem of climate change-induced corrosion, considering aspects such as the cost-benefit analysis, viability, and the large uncertainty involved in climate change evolution.
\end{abstract}

Keywords: Corrosion; Climate change; Maintenance; Eurocodes; Reinforced Concrete.

\section{Introduction}

Climate change (CC) is imposing an important pressure on all economic sectors worldwide, not only by the need of making these sectors more sustainable but also by the urgency for improving CC resilience. Within the context of the construction sector, which is an important driver of the European economy contributing to about $9 \%$ of its GDP, the European Commission has identified that technical standards are effective tools to address the challenging adaptation of European infrastructure to CC, to "incorporate win-win, lowcost and no- regret" adaptation measures [1].

The new generation of Eurocodes, which will be released by 2023, is expected to incorporate the first steps towards the adaptation of the structural design to CC. CC has direct influence on: (a) structural loads, with changes for instance in snow, thermal, and winds loads, and (b) durability of structures and buildings, with a major impact for example on reinforced concrete (RC) corrosion, which is estimated to cause a reduction of the 
service life of structures worth $3 \%$ to $4 \%$ of the GDP of industrialized countries [2].

Therefore, this paper discusses the main challenges of including considerations of CC-induced corrosion into the structural codes, presenting the existing knowledge on corrosion induced by climate change, highlighting the uncertainties related to climate models, and discussing the best approaches for the purposes of standardization. Some of the considerations here presented can be also applied when implementing other types of impact of CC in the structural codes.

The remaining document is organized as follows; Section 2 explains the role that CC has in the RC corrosion, indicating to which extent $\mathrm{CC}$ is posing an important challenge. Section 3 presents different measures for structural adaptation to climate change. In Section 4, the viability of the different solutions, their cost-benefit analyses, and the next steps towards the standardization process are discussed. Finally, in Section 5 some conclusions and future research lines are drawn.

\section{RC corrosion induced by climate change}

$\mathrm{RC}$ corrosion is a two-stage mechanism where harmful substances, that is, $\mathrm{CO}_{2}$ and chloride ions, infiltrate into concrete structures leading to rebars corrosion initiation (initiation stage). Corrosion causes loss of steel area, cover cracking, spalling, and loss of the bond between steel and concrete (propagation stage).

The infiltration rate of $\mathrm{CO}_{2}$ and chloride ion will depend on different factors, such as the level of exposition to environments rich in $\mathrm{CO}_{2}$ and chlorides (e.g., coastal areas and areas exposed to de-icing salts), environmental temperature, and humidity. These factors are closely linked to CC and its evolution given by the future economic trends. Other factors affecting the corrosion initiation and propagation rates, however not linked to $\mathrm{CC}$, are concrete composition, manufacturing conditions (e.g., vibration and curation), and loading conditions inducing to cracking. The last factors are already addressed in the existing structural codes to increase concrete durability.
For the last 30 years, the Intergovernmental Panel on Climate Change (IPCC) has provided scientific information to establish a consistent understating of CC, its impacts, and future risks. In 2000, the Special Report on Emissions Scenarios (SRES) [3] defined 6 potential greenhouse gas emission scenarios accounting for different economic and societal trends. Within them, the most pessimistic scenario in terms of $\mathrm{CO}_{2}$ generation was scenario A1FI, which relates to rapid economic growth in a more integrated world, with a strong dependence on fossil fuels, in contrast to the most optimistic, B1, corresponding to a scenario of global environmental sustainability. Subsequently, they proposed the Representative Concentration Pathways (RCPs) [4], that is, RCP2.6, RCP4.5, RCP6.0, and RCP8.5, with RCP2.6 being closer to B1 and RCP8.5 to A1FI. The last global tendencies are showing that RCP2.6 might be naively optimistic, thus in practicality, the RCP4.5 is very often proposed as the feasible optimistic scenario.

The scenarios are used by climatologists to determine climate changes with a significant level of confidence for each scenario providing a horizontal resolution of up to 9 to $12 \mathrm{~km}$ using downscaling techniques. In regards to corrosion initiation and propagation, the CC-induced variation in air temperature and relative humidity are of interest. These weather variables present an advantage to other weather variables, such as the amount of snowfall, that is, the confidence level of their estimations is larger when down-scaling from global climate models to regional models, given their low dependency on other local climate phenomena. This aspect is important in a standardization context.

Several studies have analysed the impact of CC upon the carbonation-induced corrosion when assuming different $\mathrm{CO}_{2}$ levels, relative humidity, and temperature conditions at various locations. The estimated increments of the carbonation depths are up to $45 \%$ by 2100 under the RCP 8.5 scenario (or the equivalent A1F1 scenario) when comparing with the year-2000 baseline (see e.g., $[5,6,7]$ and [8]). De Larrard et al [17] estimated the decrease on reliability for various cities in France subjected to carbonation and CC. They found a large variety of results where the effect of CC largely depended on the specific weather or each 
city. For example some cities have very humid environment that provides a natural protection from concrete carbonation and then any effect of climate change could be expected. Contrarily, in some places the reliability index was divided per 3 when passing from the more optimistic scenario (B1) to the more pessimistic one (A2).

In the case of chloride-induced corrosion, the studies report more modest values, though still relevant, reaching increments of around $15 \%$ of chloride concentration at the rebar level when comparing the 2000-year values to the RCP 8.5 by the end of the century (see e.g., [6] and [9]). Other studies report lifetime reductions varying from 2$18 \%$ [18] for corrosion initiation and up to $31 \%$ when considering the time to failure [19]. As for carbonation, it has been also reported that the extent of the effects depend on the environmental conditions at the construction place [15]. Nevertheless, there are no estimations on the effect of climate change on the combined effect of $\mathrm{CO}_{2}$ and chloride ion upon the RC corrosion, which could modify the speed of the deterioration processes.

As a consequence, the reliability and service life of $\mathrm{RC}$ structures can be highly impacted. For instance, when comparing the year 2000 and the A1FI scenario by 2100 , Stewart et al [10] estimate that the impact of increasing $\mathrm{CO} 2$ levels, temperature and humidity can increment damage risk due to carbonation-induced corrosion over $400 \%$ in some areas of Australia, and up to $15 \%$ due to chlorideinduced corrosion. Comparing the same scenarios, Saha and Eckelman [6] estimate reductions of the service life of 26 and 10 years, caused by carbonation and ion-chloride respectively, for the building stock of the Boston Metropolitan area. Pakkala et al [11] analysed facades at different locations of Finland and conclude that the increment of corrosion rates may reach up to $200 \%$ during winter in coastal areas facing to the south when comparing the year 2000 with the year 2100 under the $\mathrm{A} 2$ scenario.

\section{Measures for structural adaptation to climate change}

The presented figures highlight the need for an imminent adaptation strategy. In this regard, differentiation must be done between measures implemented during the design phase (for new structures), and those implemented during the service phase (for existing structures).

\subsection{Adaptation measures during the design phase}

Concrete composition and materials and cover depth are the main factors presented in [12] affecting structural durability (see Figure 1). Both are related, as the selection of a more dense concrete allows the reduction of the cover depth and vice versa. The typology of the structure to be designed along with its use, the production control and the environmental conditions must be considered to determine the values of these factors that guarantee the required durability performance. Precisely, local environmental exposure under a changing climate should be introduced in this definition of environmental conditions within a new generation of Eurocodes.

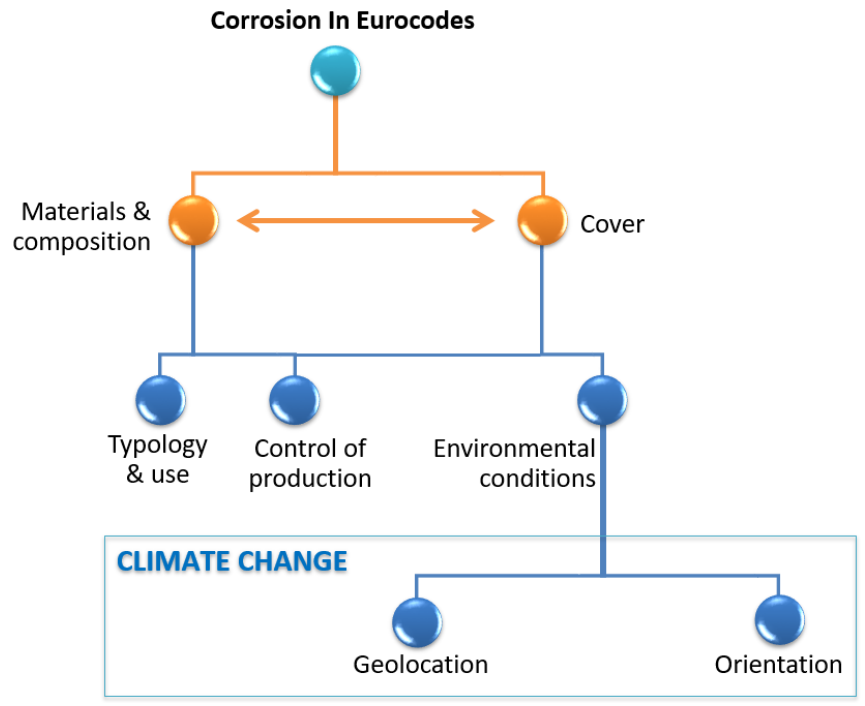

Figure 1. Mind map of the process to address $R C$ corrosion according to structural codes

The prescribed cover depth can be incremented as an initial strategy to guarantee enough durability of new structures impacted by CC. Also, increasing the concrete grade and reducing the water-cement ratio might result in more corrosion-resistant structures. Nevertheless, it is estimated that increasing design cover by up to $10 \mathrm{~mm}$ or increasing one grade the concrete compressive 
strength, which both are proposed as CC adaptation measures, would imply an increment of $1-3 \%$ of the construction costs [13]. Therefore, a more in-depth analysis should be conducted regarding these measures.

The use of concrete mixtures, such as blended and alkali-activated (AA) cements, can be also fostered within the new generation of Eurocodes. They have higher density matrices than the so-commonly used Portland cement $(\mathrm{PC})$, reducing the permeability of the harmful substances. Also, the production of AA slag cement, where the slag substitutes part of the $P C$, generates lower greenhouse gas emissions than PC, making AA slag cements a more environmentally sustainable solution. Although the slag cement has been used in the USA for more than 100 years, the feasibility of replacing PC blinders for some structural uses should be further investigated.

Regarding using more corrosion-resistant reinforcement, low carbon, stainless or galvanized steel reinforcement and glass-fiber-reinforced polymer rebars are potential solutions. Again, the cost of upgrading the reinforcement material requires a proper cost-benefit investigation.

\subsection{Adaptation measures during the service phase}

The adaptation strategies during the structural service life can be classified into two types, those aiming at preventing corrosion, that is, coating and penetrating sealants, and measures aiming at repairing damaged RC. Stewart et al [13] estimate that carbonation depths can be reduced by $10-65 \%$ by applying acrylic-based surface coatings, nevertheless, sealants are an effective solution only if applied before the chlorides have penetrated. In any case, these treatments should be performed periodically, every $10-15$ years.

Regarding the measures aiming at repairing damaged RC, identification of the extent of the damaged area is required. Whereas carbonationinduced corrosion is usually easier to identify as the affected areas are usually large, chloride-induced corrosion affects localised areas depending on the exposure of the structural components, making its identification more challenging.
Patch repair is widely used to rehabilitate corrosion-damaged RC structures. It requires to remove the affected concrete including the concrete behind the bars. In the case of chlorideinduced corrosion, attention should be paid to properly removing the corroded area, otherwise, the corrosion will spread out rapidly after the patch repair. Thus, it is effective only when the chloride ingress is local, and for that reason, patch repair in the case of chloride-induced corrosion cannot be considered as a long-term rehabilitation [14].

Realkalization presents an alternative for those structures where removal of concrete behind the reinforcement is not a viable option for structural reasons. This option is more environmentally sustainable and requires lower maintenance than the patch repair and coating. Also, electrochemical chloride extraction can be used. Although there is no knowledge on the duration of its effectiveness, given that it is a relatively new technique, theoretically, it can be effective during 15-20 years. Nonetheless, this type of interventions is usually more expensive.

\section{Viability of the solutions}

Given the large impact that structural codes have on the economy of the countries subjected to them, the inclusion of recommendations and rules should be carefully considered. The main challenges of standardising CC adaptation measures are the following; (a) climate change, and thus its impact, is highly dependent on the global socio-political context; (b) the adaptation measures during design-phase, despite being effective measures to extend the service life of structures subjected to CC-induced corrosion, are not always cost-effective; and (c) applying measures during service life is usually more expensive than the design-phase measures. Therefore, the cost-benefit analysis of the different measures should be addressed.

Nonetheless, cost-benefit analyses are challenging and subject to many assumptions. Aspects such as the expected damage cost of an inadequate adaptation strategy and the consequent repair costs should be evaluated against the cost of the adaptation measure. These analyses should 
account for the uncertainty of climate change to provide a meaningful decision-support tool.

Authors such as [15] and [16] have analysed to which extent increasing the cover thickness 5 or 10 $\mathrm{mm}$ of several structural members are costeffective under different climate scenarios. They conclude that the efficiency of this adaptation measure will depend on the climatic conditions, structural typology, size and discount rate.

Even when only the solutions that are costeffective under a given climate scenario are taken, underestimating the impact of climate change by considering very optimistic scenarios would result in significant maintenance costs, whereas its overestimation would imply an unnecessarily waste of resources in the design phase. Therefore, this paper proposes to include adaptation measures in the new generation of Eurocodes through a twofold-approach, that is, (i) adaptation measures implemented during the design-phase to tackle the impacts of climate change associated with a given level of confidence; and (ii) the future impacts of CC should be covered in a post-design stage, that is, through preventive maintenance, which will be defined as a function of the updated values of the $\mathrm{CC}$ evolution.

Most of the European codes, guidelines and specifications on structural durability dismiss the potential of maintenance to ensure the required durability during the structural working life. They explicitly assume that an "adequate maintenance" is a prerequisite to guarantee structural durability (e.g., $[21,22,23])$, whereas other standards are more specific by providing some maintenance recommendations [24]. For instance, in fib17 [25], which focusses on structural management and maintenance, durability plays a central role, and introduces a 3-level classification of the seriousness of the durability failure. Inspection and monitoring are seldom addressed (e.g., [26]), although some refer to the role of inspection as a means to guarantee the required durability [22, 24]. In this regard, Eurocodes should prescribe specific maintenance recommendations concerning climate change.

The adaptation of Eurocodes to the different design traditions and geographical characteristics of the Member States is conducted through the so- called NDPs (Nationally Determined Parameters). They are parameters chosen by the countries to avoid inconsistencies with their own codes and standards, however, some recommended values are proposed by Eurocodes to help the harmonization. A critical aspect when introducing $\mathrm{CC}$ to the second generation of Eurocodes relates to the climatic maps. Although the Member States will be able to choose their NDPs, cross-border convergence of the maps should be guaranteed. In this regard, a recent scanning conducted by the EU [27] concludes that the existing climate-related NDPs present a high harmonization level and no important differences can be appreciated between most of the borders. It is clear that NDPs provides European codes with the capacity to adapt to the different national realities, but also, that introducing a large number of new NDPs will make the harmonization among the Member States difficult.

Standardization and cost-effective decision making should also be supported by five key elements [20]: Institutional Engagement; Decision relevant information; Institutional design; Tools for planning and policymaking; and Resources. Implementing these challenges is not an easy task because it requires many efforts and interactions from all the actors involved in the problem: endusers, owners academia, standardization bodies etc. These factors should be accounted for in the development and implementation of new standards.

\section{Conclusions}

This paper has presented the impact that climate change will have on the corrosion process of RC structures and the potential solutions to face such a challenge through the standardization of adaptation measures in a future generation of Eurocodes. Despite focused on corrosion, some of the presented insights can be extrapolated to other types of CC impact, such as the updating of thermal actions or timber decay.

Beyond the geographical differences across countries, the main challenge of standardising adaptation measures is posed by the uncertainty related to climate change, which mainly depends on the trajectory of greenhouse-gas emissions. For 
that reason, a resilience-based approach should be proposed, that is, including adaptation measures during the design phase to tackle the certain impact of climate change, and to be prepared for the uncertain impact of $\mathrm{CC}$, by implementing design and maintenance measures, which should be specified in the new generation of Eurocodes.

The impact that CC has on the chloride-induced corrosion seems to be smaller than the carbonation-induced corrosion, nevertheless, the efficiency of the treatments to remove it is smaller and the kinematics of the deterioration process could be faster, thus chloride-induced corrosion might pose a more challenging issue.

The use of new materials and mixtures have been also discussed in this paper, nevertheless, more knowledge is required in this regard to characterise and model its durability performance after repair. Besides, improving the technology to obtain more cost-efficient coatings and sealers would help to reduce the adaptation costs.

It is noted that there is a compound effect of chloride- and carbonation- induced corrosion processes, however, the effect of climate change on this combined effect has not been quantified yet. Thus, further research on this regard should be conducted.

\section{References}

[1] Union Innovation, Communication from the Commission to the European Parliament, the Council, the European Economic and Social Committee and the Committee of the Regions, A new skills agenda for Europe. Brussels.

[2] G. Schmitt, et al., Global needs for knowledge dissemination, research, and development in materials deterioration and corrosion control, World Corrosion Organization (2009) 1-44.

[3] N. Nakicenovic, J. Alcamo, A. Grubler, K. Riahi, R. Roehrl, H.-H. Rogner, N. Victor, Special report on emissions scenarios (SRES), a special report of Working Group III of the intergovernmental panel on climate change, Cambridge University Press, 2000.
[4] C. W. Team, Climate change 2014: synthesis report (2014).

[5] S. Talukdar, N. Banthia, J. Grace, S. Cohen, Carbonation in concrete infrastructure in the context of global climate change: Part 2Canadian urban simulations, Cement and Concrete Composites 34 (8) (2012) 931-935.

[6] M. Saha, M. J. Eckelman, Urban scale mapping of concrete degradation from projected climate change, Urban Climate 9 (2014) 101-114.

[7] L. Peng, M. Stewart, Spatial time-dependent reliability analysis of corrosion damage to RC structures with climate change, Magazine of Concrete Research 66 (22) (2014) 11541169.

[8] B. Mizzi, Y. Wang, R. P. Borg, Effects of climate change on structures; analysis of carbonation-induced corrosion in reinforced concrete structures in Malta, in: IOP Conference Series: Materials Science and Engineering, Vol. 442, 2018, p. 012023.

[9] H. Xie, Y. Wang, J. Gong, M. Liu, X. Yang, Effect of global warming on chloride ion erosion risks for offshore RC bridges in China, KSCE Journal of Civil Engineering (2018) 1-7.

[10] M. G. Stewart, X. Wang, M. N. Nguyen, Climate change impact and risks of concrete infrastructure deterioration, Engineering Structures 33 (4) (2011) 1326-1337.

[11] T. A. Pakkala, A. Kolio, J. Lahdensivu, M. Pentti, Predicted corrosion rate on outdoor exposed concrete structures, International Journal of Building Pathology and Adaptation.

[12] EN, EN 1992 Eurocode 2: Design of concrete structures, CEN, Brussels, 2005.

[13] M. Stewart, X. Wang, M. Nguyen, Climate change adaptation for corrosion control of concrete infrastructure, Structural Safety 35 (2012) 29-39.

[14] M. G. Grantham, Concrete repair: A practical guide, CRC Press, 2011.

[15] E. Bastidas-Arteaga, M. Stewart, Economic assessment of climate adaptation strategies 
for existing reinforced concrete structures subjected to chloride-induced corrosion, Structure and Infrastructure Engineering 12 (4) (2016) 432-449.

[16] M. Stewart, E. Bastidas-Arteaga, Corrosion of concrete and steel structures in a changing climate, in: Climate Adaptation Engineering, Elsevier, 2019, pp. 99-125.

[17] De Larrard T, Bastidas-Arteaga E, Duprat F, and Schoefs F. Effects of climate variations and global warming on the durability of RC structures subjected to carbonation, Civil Engineering and Environ- mental Systems, (2014) 31(2):153-164.

[18] Bastidas-Arteaga E, Chateauneuf A, SánchezSilva $M$, Bressolette $P$, and Schoefs $F$. Influence of weather and global warming in chloride ingress into concrete: A stochastic approach. Structural Safety (2010), 32(4):238-249

[19] Bastidas-Arteaga E, Schoefs F, Stewart M G, and Wang $X$. Influence of global warming on durability of corroding RC structures: A probabilistic approach. Engineering Structures (2013), 51:259-266.

[20] Bastidas-Arteaga E, Stewart M G. Recommendations for Infrastructure Decision-Makers Under a Changing Climate. In E. Bastidas-Arteaga, M.G. Stewart (Eds.), Climate Adaptation Engineering: Risks and Economics for Infrastructure DecisionMaking. Butterworth-Heinemann. (2019) 353-360.

[21] EN 1990 (2002): Eurocode - Basis of structural design. The European Union Per Regulation 305/2011, Directive 98/34/EC, Directive 2004/18/EC.

[22] Probabilistic Model Code, JCSS. Joint Committee on Structural Safety (2006).

[23] DM 14/01/2008: Norme Tecniche per le Costruzioni (Italian Code) Ministero Delle Infrastrutture, Decreto 14 gennaio 2008 (G.U. 4 febbraio 2008 n. 29 - S. O. n. 30).

[24] CEB Bulletin n.183: Durable Concrete Structures-CEB Design Guide (1992); ISBN 978-0-7277-1620-0; 120 pages.
[25] fib Bulletin n.17: Management, Maintenance and Strengthening of Concrete Structures (Technical Report, April 2002).

[26] fib Bulletin n.86: Safety and performance concepts: Reliability assessment of concrete structures-Guide to good practice, August 2018.

[27] Sousa, M.L., Dimova, S. Athanasopoulou, A., lannaccone, S. Markova, J., State of harmonised use of the Eurocodes, EUR 29732 EN, Publications Office of the European Union, Luxembourg (2019) 